\title{
MODERN TRENDS IN CONTINUOUS PROFESSIONAL DEVELOPMENT OF FOREIGN LANGUAGE TEACHERS (ON THE BASIS OF THE BRITISH COUNCIL RESEARCH)
}

\begin{abstract}
Research conducted by the British Council concerning modern continuous professional development of teachers has been analyzed. The issue concerning foreign language teachers' professional development has been considered. Productive approach to this process that gives a teacher the opportunities to define aspects of their professional activities that are in need of improvement and introduce appropriate strategies of their own professional development has been characterized. Direct connection between continuous teachers' professional development and the level of students' academic achievements has been stressed. Key characteristics of effective professional development have been defined, namely: being correspondent to actual needs of teachers and students; teachers' involvement into the decision making concerning the content and the fulfillment of professional development; provision of cooperation and teachers' experience exchange; collegiality presupposing common work of teachers and educational establishments in general; practicality, that is the fulfillment of professional development directly in the process of teachers' work in class; obligatory character of professional development as indispensable part of teachers' work; constant reflection and research; prioritizing academic achievements of students as the main stimulus for professional learning of teachers; continuity of professional development and its consideration not as separate forms of work. Modern widely used forms of teacher professional development have been analyzed, namely: self-education, common lessons planning with their further analysis; professional discussions concerning new teaching techniques and the appropriateness of their application; reflexive groups for teaching experience exchange and lessons analysis (video recording of lessons or students' works), observation/attending teachers' lessons with their further discussion in constructive form and without formal evaluation; participation in professional learning communities to solve urgent issues concerning school work and teachers' professional activities; common work of teachers with curricula for detailed studying of problematic issues and their elimination; common teachers' elaboration of learning materials for definite groups of students; participation in mentoring programs; work in online educational communities It has been proved that modern professional development of foreign language teachers shifts its focus from the competency of a teacher to the level of students' academic achievements which is the direct indicator of a teacher's competency.

Keywords: continuous professional development, academic achievements, forms of teacher professional development, teachers of foreign languages, the British Council.
\end{abstract}

\section{INTRODUCTION}

In modern pedagogical literature the term "continuous professional development" (CPD) is frequently used. It has a lot of definitions and directly related to teachers' work 
and their professional upgrading. People, not directly related to teachers' work, used to consider CPD as in-service teacher training, but in reality this notion is considerably wider. In the 21st century the notion of CPD presupposes a range of activities and practical means which allow to make this process constant, social, contextual, scientifically substantiated, favorable for teacher's professional development, increase of students' academic achievements and provision of qualitative educational establishments' work.

It should be mentioned that CPD is especially important for foreign language teachers as under the condition of education globalization these subjects are particularly demanded and demands to their teachers are constantly increasing. Traditional approaches to CPD of foreign language teachers tended to concern exclusively practical methods of foreign languages teaching (teaching reading, writing, technology usage, class work organization etc.). Language and methodical competency of foreign language teachers is surely a basis of their professional activities. But it is obvious that the effective work of the mentioned teachers presupposes more varied approach to their professional development. Modern CPD presupposes not only the subject knowledge, but also the organization of learning and providing its qualitative process in the class with active students' participation and sustaining their interest to the learning, ability to choose and elaborate the necessary educational materials, provision of appropriate assessment of students' academic achievements, increase of teachers' motivation to further development, self-development, cooperation, work in communities, self-analysis and scientific research. That's why when the decision about forms and methods of teachers' professional development is made, it's necessary to take into consideration all these aspects and involve teachers into the process of decision making concerning the choice of those professional development kinds which are urgent, necessary and appropriate for them. CPD must be practical and effective, thus provide teachers' reflection, encourage further research, experience exchange, and have positive impact onto students' academic achievements.

A considerable advantage of modern CPD is leaving behind the idea of "labeling" teachers (such as a beginner teacher, experienced teacher etc.) which has been the only criterion of their qualification for quite a long time. Teachers' knowledge is multilateral the same teacher can be competent in some aspects of his/her professional activities but have insufficient qualification level in some other spheres of professional work. For instance, a teacher may show a high level of foreign language speaking teaching skills but have not enough skills of assessing its process and its effectiveness. Another teacher may have excellent theoretical knowledge of language systems but have no confidence in oral foreign language communication and in the ways of teaching it to students. That's why there should be a productive approach to CPD which will give teachers the possibility to define those aspects of their professional activities which are in need of improvement and introduce the appropriate strategies of professional development.

\section{THE AIM OF THE STUDY}

Taking into consideration the urgency of the defined problem the aim of the article is to study modern trends of CPD tendencies, define main characteristics of this process and its most widely spread and effective forms on the basis of the British Council research results and determine the prospects of their use in the educational system of Ukraine.

\section{THEORETICAL FRAMEWORK AND RESEARCH METHODS}

The issue of CPD of teachers in the modern educational environment has been considered in the works of such scientists, as H. Barrar (Barrar, 2008), S. Borg (Borg, 2015), K. Broad (Broad, 2006), C. Day (Day, 1999), P. Earley (Earley, 2014), I. Fung (Fung, 2008), 
V. Porritt (Porritt, 2014), J. Westbrook (Westbrook, 2013) and others. Considerable attention to the problem of CPD was paid by the British Council (British Council, 2015) within the project "Teaching for Success". The motto of this research project is: "Educational system can only be successful if teachers who work in it are successful" (UNESCO, 2014). Taking into account substantial research of scientists and the British Council in this area, it is considered as appropriate to fulfill comparative pedagogical analysis of foreign language teachers' professional development system in the developed countries and Ukraine to define their common and different features and to outline prospects of optimizing the system of teachers' professional development in Ukraine on the basis of using positive European experience.

\section{RESULTS}

According to scientific research of S. Borg, ensuring quality of teachers' work at all stages of their professional activities is the key factor in improvement of students' learning quality. Thus, it is necessary to focus on effective teachers' professional learning that is called CPD (Borg, 2015).

The most widely used definition of CPD that can be found in modern scientific literature is the definition of an American researcher C. Day, according to whom CPD is any natural learning experience as well as conscious and planned kinds of activities that are directly or indirectly bring benefit to a person, group or establishment and are aimed at the improvement of their work quality. In the process of CPD teachers alone or in cooperation with colleagues develop critical thinking, knowledge and skills, achieve emotional maturity, which are necessary for their qualitative professional activity (Day, 1999). From the definition it is clear that CPD is characterized by multilateral nature (concerns teachers' behavior, their knowledge, emotions and thinking); natural essence (it takes place in the process of teaching activity); planning (teachers choose forms and kinds of this process). Besides, CPD benefits not only teachers, but students, educational establishments and all the participants of the educational process (both direct and indirect). And this is the main tendency of modern CPD - focusing not only on the personal and professional development of teachers, but also on the achievements of educational establishments' aims, improvement of students' academic achievements. Moreover, some researchers, such as P. Early and V. Porritt, stress that improvement of students' academic achievements is the primary aim of CPD and that students' needs are the decisive point in making decisions concerning forms and kinds of this process (Early\&Porritt, 2014).

Thus, it is clear that CPD of teachers is the decisive factor in providing successful educational establishments, qualitative teachers' work and high students' academic achievements.

For the majority of people who do not have direct relation to teachers' work and cannot clearly understand the essence of CPD, this process is associated with conferences, seminars and in-service teacher training, but in reality it includes much more kinds of work at the level of a separate teacher as well as at the level of a country or the world. In the course of research conducted by scientists K. Broad and M. Evans (Broad \& Evans, 2006), D. Orr (Orr et al., 2013) and H. Timperley (Timperley et al., 2008) key characteristics of effective professional development that has positive and continuing impact on teachers, students and educational establishments have been defined:

- meeting real students and teachers' needs;

- teachers' involvement into the decision making concerning the content and the course of CPD;

- provision of teachers 'cooperation and experience exchange; 
- collegiality that presupposes common work of teachers as well as educational establishments and educational system in general;

- practicability that is the fulfillment of professional development directly in the process of teachers' work in the classroom;

- obligatory nature of CPD as an indispensable part of teachers' work;

- constant reflection and research;

- priority of students' academic achievements as the main stimulus for teachers' professional learning;

- continuity of professional development and considering it not as separate forms of work (Broad \& Evans, 2006).

Approaches to professional development that correspond all these characteristics are called developing, socio-constructive and research-oriented. All of them represent principles of common, social scientifically-substantiated professional learning that takes place in a definite context and according to which teachers make the main decisions about forms and kinds of their professional development. Basically, it means the usage of the CPD approach that is relevant to the needs of teachers, students, educational establishments, provides teachers with opportunities to choose, encourages them to learn together with colleagues and exchange their experience, use results of their learning in practice. Different forms of CPD correspond to these characteristics:

- self-study (research projects aimed at providing teachers with possibilities to analyze their learning process);

- common lesson planning with further analysis of their advantages and disadvantages;

- professional discussions of new teaching methods and appropriateness of their usage;

- reflective groups for teaching experience exchange and lessons analysis (video recording or students' works);

- observation of teachers' work in class with further constructive discussions and with no formal assessments;

- participation in professional learning communities to solve schools and teachers' urgent issues related to their professional activities;

- common teachers' work on curricula to analyze their problematic aspects, ways of their elimination, improvements of curricula and their optimization;

- common elaboration of teaching materials for definite groups of students;

- taking part in mentoring projects where more experienced and specially trained teachers support and direct the development of less experienced;

- participation in online learning communities (Timperley et al., 2008).

It is important to mention that new approaches to organization and carrying out of CPD compliment and modernize but in no way reject its traditional forms, such as seminars and courses. American researcher D. Orr is convinced that seminars which are used in combination with other professional development forms can be effective and appreciated by scientists and practicing teachers (Orr et al., 2013). But the key factor here is the consideration of seminars as a part of a wider CPD strategy and not its one separate form.

Another important factor is the absence of some common sample for CPD that would ensure success in any environment. Contextual variation is an indispensable characteristic of this process - what works well in some definite context may appear to be ineffective in another one. That is why the implementation of some definite CPD strategy must be to some extent localized. In other words, the decision about the usage of such 
forms as research projects and common lesson planning doesn't ensure effective teachers' professional learning. Kinds of CPD must be chosen and implemented with consideration of teachers' previous experience, their knowledge, needs and views and must correspond to peculiarities of educational system in which they are used (UNESCO, 2014).

According to S. Borg's researches, present day CPD of foreign language teachers must presuppose four stages:

1. Awareness of the professional pedagogical activities.

2. Understanding of its meaning and significance.

3. Being involved into the process of competent professional pedagogical activities.

4. Integration into a professional pedagogical environment and constant experience exchange (British Council, 2015).

Undergoing these stages a teacher has to master a high level of language competence $(\mathrm{C} 2)$, reach an appropriate level of educational and scientific qualification $(\mathrm{PhD})$. Besides, at all stages of CPD a foreign language teacher must constantly improve his/her own professional activities which concern lesson and educational process planning, taking into consideration students' needs and interests, organization and control of lesson process, subject matter knowledge, effective use of learning materials, literate assessment of students' academic achievements, IT implementation, responsibility for one's own professional development, provision of inclusive education, multi-language approaches usage, taking into consideration modern educational trends, understanding educational policy and practice (Borg, 2015).

It is necessary to consider in detail the above mentioned aspects of foreign language teachers' professional activities, qualitative provision of which is the key task of CPD

Common lesson and general education process planning presupposes the necessity to define students' educational needs, aims and results of learning; choose and elaborate kinds of learning activities, resources and materials which will be of interest to students and correspond to the aims of lessons; to divide lessons into subsequent stages with the appropriate allocation of time; to plan the work at the blackboard; to fulfill interactive and group lesson work, provide differentiated learning (for students with different knowledge level); to predict problems that can appear in the course of the lesson and to eliminate them; to provide analysis of students' academic achievements; to plan kinds of work which will help students to develop different abilities and skills; to relate a lesson with a previous and next ones; to plan a range of subsequent lessons which presuppose the revision of the learning content; to analyze lessons' effectiveness with consideration of students' response and other factors.

Taking into consideration students' needs and interests presupposes: making decisions about organization and carrying out of learning process and its evaluation on the basis of a range of students' characteristics (level of their academic achievements, age, interests, preferable forms and methods of learning, group dynamics, motivation to learning (general and subject); educational, social, cultural and linguistic contexts of learning; level of individuality, personal qualities); research of learning theories and their application in a definite educational context and in separate groups of students; analysis of students' needs and the application of its results in practice; understanding the influence of learning environment onto the students; analysis of one's own attitude to students and its influence onto their academic achievements (Borg, 2015).

Organization of lessons and control of their carrying out presupposes: control of the pace and distribution of time allocation; strict division of a lesson into stages; adjustment of atmosphere in class to educational needs; quick reaction to unexpected change of 
the planned lesson course; effective use of resources and equipment; clear instructions; relevant explanation of learning aims and content; checking the understanding of the latter by students; usage of the foreign language according to the level of students' knowledge; making decision (both by students and teachers) about the language, native or foreign, which is to be used in the process of a lesson organization and tasks' explanation; constant control of students' active role in class work and increasing their motivation to learning; establishment and sustainability of the discipline; using different activities which presuppose diverse interactive kinds of work; changes in a lesson plan to use possibilities for learning which appear in the course of a lesson; establishment and sustainability of the positive learning environment; analysis of the lesson organization, determining its advantages and disadvantages, making some relevant changes.

Knowledge of a subject matter presupposes: perfect knowledge of the target language to set a role model for students; selection of appropriate methods and teaching resources for practical work at different aspects of a target language learning (grammar, vocabulary, phonology, speaking, listening, writing and reading, communicative activity, sociolinguistic skills, kinds and standards of a target language, comparative analysis of a native and target languages); using professional literature and references on subject matter; knowledge of language teaching theories and their application in a specific teaching context; analysis of advantages and disadvantages of the subject knowledge for its further improvement.

Effective usage of learning resources. While choosing resources it is important to be conscious of their diversity, possibilities of media application (digital, audio-visual, printed) which are relevant to students' needs and learning context; possibilities of common elaboration of learning materials, creation of the content by students themselves; defining clear criteria for selection of materials and resources depending on the students' needs and correspondence to the curriculum. Elaboration and adaptation of materials and resources must presuppose a range of authentic (licensed) teaching methods which are relevant to students' needs and demands of the curriculum; which are professional, interesting, accessible, used in correspondence with copyrights and are contextually relevant; which can be shared with colleagues and used in cooperation with them. Materials must be effectively used with equipment and technologies to encourage learning. For further use of materials it is necessary to elaborate and sustain a system of their accumulation and storage. Besides, the rationality of resources usage must be understandable for teachers, students and other participants of educational process. Here the evaluation of materials and resources' effectiveness as well as their relevance to students' needs is compulsory (Timperley, 2011).

Literate assessment of academic achievements presupposes application of principles and practice of assessment, aimed at defining the level of students' progress in education; using different kinds of assessment and analysis; ensuring assessment at different stages of learning process to monitor students' knowledge and organize further teaching process; determining appropriate assessment criteria and their consecutive and logical application; analysis of students' typical mistakes and ensuring their constructive elimination; constant students' involvement in self-evaluation and reciprocal assessment, as well as constant improvement of these skills; preparation of students to final assessment (on the level of a class or school), keeping the assessment register and its data; informing students, parents and other participants of the learning process about results of learning; analysis of effectiveness of students' academic achievements' assessment.

Integration of information technologies presupposes elaboration of effective strategies to use appropriate digital content; following instructions to use Internet safely; evaluation 
of potential efficiency and relevance of the digital content, instruments and platforms to achieve desired results of learning; using technologies in the process of creating learning materials; providing different kinds of work using appropriate digital content, instruments and platforms; elaboration of effective strategies to solve potential technical problems; using technologies to perform administrative tasks according to the instructions concerning data protection; encouraging self-study with the use of digital content and technologies inside the classroom as well as out of it; encouraging common and active learning within online communities, using online instruments and platforms; analysis of effective integration of information technologies into the learning process.

Responsibility for one's own professional development presupposes understanding one's own professional needs, interests and learning priorities to define aspects which are in need of improvement; determination of short and long term aims of professional development; realizing available forms and methods of development to achieve some definite professional purposes; using technologies to encourage professional development; be knowledgeable in new tendencies of education development especially in relation to foreign languages; selection and application of appropriate opportunities and resources of professional development which in their turn presuppose cooperation with colleagues and other professionals, reflective activity, scientific and practical research, participation in conferences, learning courses, study of professional literature and writing scientific articles, membership and work in professional teachers' associations, observation of colleagues' lessons and giving presentation lessons, analysis and evaluation of CPD advantages and its influence onto teachers' work in classroom and students' academic achievements.

Provision of inclusive education presupposes awareness of students' being different in their perception of language environment, their cognitive, learning and physical abilities, social environment, behavior, disabilities, age, sex, race and ethnicity, religion and views. A foreign language teacher can use pedagogical strategies to encourage inclusive education in encouraging educational environment; help students to define, achieve and evaluate their individual learning aims; realize his/her own views and their possible influence on establishing and sustaining inclusive educational environment; assess every student's achievements and provide them with opportunities to demonstrate their success in education; have the same positive and respectful attitude to all students; involve parents, students and other participants of educational process to creation of inclusive educational environment; analyze the created inclusive educational environment and take steps in order to improve it (Borg, 2015).

Application of multilanguage approaches presupposes: the awareness of multilanguage essence of society, communities, schools; using pedagogical strategies to ensure inclusive education in encouraging multilanguage educational environment; individual assessment of students with consideration of their linguistic environment; provision of students with equal possibilities for using their native language for adequate understanding of the learning content; making pedagogical decisions taking students' linguistic diversity into consideration; analysis of effectiveness of multilanguage approaches' application to encourage learning.

Taking into account modern trends in education presupposes teachers' critical thinking, their readiness to solve educational problems, cooperation and communication of teachers, using their creativity, imagination, digital literacy, leadership and personal development to correspond to modern trends in education development; selection of appropriate methods and educational resources to introduce, develop and evaluate new trends in education; teachers' critical analysis of their own awareness concerning modern 
educational trends and readiness to advance this awareness. Understanding educational policy and practice presupposes being knowledgeable in national, regional and institutional educational policy; possessing relevant information about international, national, regional and institutional educational practice; performing professional pedagogical activities which correspond to current educational policy and aims of education; extension of learning possibilities for students and protection of their rights; realization of educational reforms, inclusive learning, increase of literacy level, provision of accessibility, equality of learning possibilities, diverse forms of studying and its inclusion; ability to elaborate and optimize curricula, introduce new methods of teaching, modern approaches to assessment; understanding standards of foreign languages learning; integration of information technologies in education, constant analysis of educational policy and practice influence onto teachers' professional activities and students' academic achievements (British Council, 2015).

\section{CONCLUSIONS}

Thus, on the basis of the research conducted by the British Council and its analysis there can be made a conclusion that modern trends of CPD take into consideration a much wider range of issues related with professional activities of foreign language teachers than just their language competency and pedagogical craft. Having compared systems of foreign language teachers' professional development in Ukraine and other developed European countries we have determined that in the latter ones teachers' professional development is carried out at all the stages of their professional activities and concerns the following aspects: planning lessons and learning process in general, taking into account students' interests and needs, organization and control of the lesson course, knowledge of the subject matter, effective use of educational resources, literate assessment of students' academic achievements, integration of information technologies, responsibility for one's own professional development, provision of inclusive education, taking into account modern trends in education, understanding educational policy and its implementation.

It is an undeniable fact that teacher's work in modern society becomes more and more difficult which can be explained with the increase of demands to ensuring a qualitative and effective learning process. Competency of a foreign language teacher is not limited to the level of language knowledge but presupposes the possibility to provide qualitative teaching taking into account a complex of difficult processes that take place in class as well as out of it. Modern CPD is focused not on the professionalism of teachers but on the academic achievements of their students which is the main indicator of teachers' competency. Taking all the above mentioned into account, modern teachers of foreign languages must be knowledgeable and ready to continuous professional development to correspond to the demands of present days.

\section{REFERENCES}

1. Borg, S. (2015). Contemporary perspectives on continuous professional development. British Council. Retrieved from http://51431fdb1a97060163cc05795c414fcde9449273ebc896b6599f.r19.cf1.rackcdn.com/Contemporary\%20Perspectives \%20on\%20Continuing\%20Professional\%20Development.pdf.

2. Borg, S. (2015). Researching language teacher education. In B. Paltridge \& A. Phakiti (Eds), The Continuum companion to research methods in applied linguistics, Second ed., 541-560. 
3. British Council (2015). Continuing Professional Development (CPD) Framework for Teachers. Retrieved from http://www.teachingenglish.org.uk/ sites/teacheng/files/CPD\%20framework $\% 20$ for $\% 20$ teachers_WEB.PDF.

4. Broad, K., \& Evans, M. (2006). A review of literature on professional development content and delivery modes for experienced teachers. Toronto: Canadian Ministry of Education.

5. Day, C. (1999). Developing teachers: The challenges of lifelong learning. London: Falmer Press.

6. Earley, P., \& Porritt, V. (2014). Evaluating the impact of professional development: The need for a student-focused approach. Professional Development in Education, 40 (1), 112-129.

7. Orr, D., Westbrook, J., Pryor, J., Durrani, N., Sebba, J. and Adu-Yeboah, C. (2013). What are the impacts and cost effectiveness of strategies to improve performance of untrained and under-trained teachers in the classroom in developing countries? A systematic review. London: EPPICentre, University of London.

8. Timperley, H. (2011). Realizing the power of professional learning. New York, NY: Open University Press.

9. Timperley, H., Wilson, A., Barrar, H. \& Fung, I. (2008). Teacher professional learning and development: Best evidence synthesis iteration (BES). Wellington, New Zealand: Ministry of Education.

10. UNESCO. (2014). Teaching and learning: Achieving equality for all. $11^{\text {th }}$ EFA global monitoring report. Paris: UNESCO. 